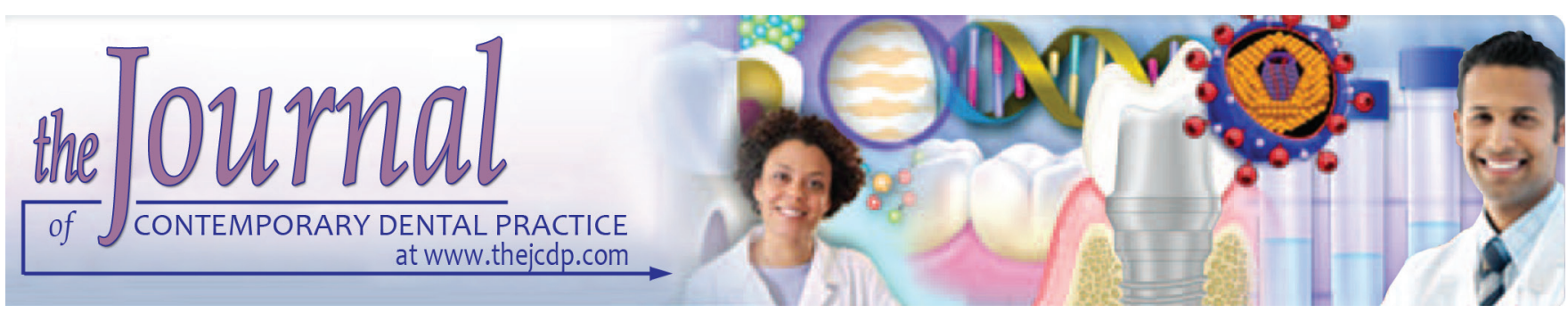

\title{
Comparison of Adhesion of a Novel Pre-sintered Cobalt-Chromium to Pre-sintered Zirconia and Cast Nickel-Chromium
}

${ }^{1}$ Elie E Daou, ${ }^{2}$ Mutlu Özcan, ${ }^{3}$ Pascale Salameh, ${ }^{4}$ Nadin Al-Haj Husain, ${ }^{5}$ Ziad Salameh

\begin{abstract}
Aim: This study compared the bond strength of pre-sintered Ceramill Sintron to pre-sintered zirconia and cast nickelchromium (NiCr).
\end{abstract}

Materials and methods: Specimens $(n=60)$ (diameter: $15 \mathrm{~mm}$; thickness: $2 \mathrm{~mm}$ ) were prepared $(\mathrm{n}=20 /$ group) (Ceramill Sintron, Ceramill $\mathrm{Zi}$, and Wirobond 99). Disks were layered with vita VM ceramic $(4 \mathrm{~mm})$. Specimens were randomly divided into two subgroups. Only one subgroup was thermocycled. Specimens were tested under shear strength. Energy-dispersive $X$-ray (EDX) mapping was done on one disk of each material before and after ceramic layering.

Results: Failure types were mostly mixed failures. Significant difference was found between the three materials for $Y$ and $Z$ failure types ( $p$-values: 0.032 and 0.010 respectively). Thermocycling had no major effect on the results reported. Considering Fmax (force-inducing bonding failure) registered, significant difference was found between the control group and milled alloys groups. No significant difference was found between Ceramill Sintron and Zi. The EDX mapping showed a net increase in the control group oxide layer, whereas only slight increase and decrease were reported for $\mathrm{Zi}$ and Sintron respectively.

\footnotetext{
${ }^{1}$ Department of Prosthodontics, Faculty of Dental Medicine School of Dentistry, Beirut, Lebanon

${ }^{2}$ Dental Materials Unit, Center for Dental and Oral Medicine University of Zürich, Zürich, Switzerland

${ }^{3}$ Department of Research and Prosthodontics, Faculty of Medical Sciences and Medicine, Beirut, Lebanon

${ }^{4}$ Department of Reconstructive Dentistry and Gerodontology School of Dental Medicine, University of Bern, Bern, Switzerland

${ }^{5}$ Department of Research and Prosthodontics, Faculty of Dentistry and Dental Medicine, Beirut, Lebanon

Corresponding Author: Elie E Daou, Department of Prosthodontics, Faculty of Dental Medicine, School of Dentistry Beirut, Lebanon, e-mail: dreliedaou@gmaail.com/dreliedaou@ yahoo.com
}

Conclusion: When compared with cast $\mathrm{NiCr}$, novel Ceramill Sintron has higher bond strength, comparable to Ceramill $\mathrm{Zi}$. Thermocycling had no major effects on the results.

Clinical significance: Ceramic-alloy bonding is a primary factor in the prosthesis' longevity.

Keywords: Computer-aided design/computer-aided manufacturing, Pre-sintered cobalt-chromium, Shear bond.

How to cite this article: Daou EE, Özcan M, Salameh P, Al-Haj Husain N, Salameh Z. Comparison of Adhesion of a Novel Presintered Cobalt-Chromium to Pre-sintered Zirconia and Cast Nickel-Chromium. J Contemp Dent Pract 2018;19(7):816-823.

Source of support: This project has been funded with support from the National Council for Scientific Research in Lebanon.

Conflict of interest: None

\section{INTRODUCTION}

Although the trend in modern dentistry is to use metalfree restorations, conventional materials successfully used over many decades still keep their role as dental prostheses. Nonprecious metal alloys have proved longterm prognosis. This class of alloys has been adopted to reduce precious metal alloys' high cost. These alloys have permitted high-quality treatment for a large number of patients, unquestionably needed where framework's high strength is required. ${ }^{1}$

Porcelain-metal strong bond is a first requirement for long-term success of metal-ceramic restorations. It must resist both transient and residual thermal stresses and mechanical forces encountered in clinical function. ${ }^{2}$ Core surface roughness, wetting properties, cooling rate systems, presence of flaws, residual stress arising from difference of thermal expansion and contraction between materials, and viscoelastic and elastic properties are factors that influence core-veneer interface. ${ }^{3}$ Therefore, it is essential to focus onto metal-ceramic interfaces 
behavior. ${ }^{4}$ Metals and porcelains have to be chemically, thermally, mechanically, and esthetically compatible. ${ }^{5}$ Some degree of coefficients of thermal expansion (CTE) matching is a prerequisite. ${ }^{6}$

Although base-metal alloys present many superior mechanical properties, some disadvantages like poor biocompatibility, low corrosion resistance, and porcelain discoloration are often cited. ${ }^{7}$ However, performances and properties of metal/ceramic complex are not completely defined. ${ }^{8}$ Porcelain chipping or fracture may occur within ceramic substrate or at the metal-ceramic interface. ${ }^{9}$ Alloy composition influences ceramic-core bond strength. ${ }^{10}$ Air-particle abrasion with $\mathrm{Al}_{2} \mathrm{O}_{3}$ can improve shear bond strength between metal and layering ceramic. ${ }^{1}$

While manual casting technique was mainly used for nonprecious metal alloys processing, computer-aided design/computer-aided manufacturing (CAD/CAM) techniques were introduced. Cobalt-chromium (CoCr) frameworks were fabricated via selective laser melting or milling from fully sintered blanks. These methods needed costly investments. The two latter processing options were therefore, mainly reserved for production centers specialized in industrial fabrication of $\mathrm{CoCr}$ restorations.

In the early 1990s, yttrium oxide partially stabilized tetragonal zirconia polycrystal (Y-TZP) was made available to dentistry as a core material for all-ceramic restorations through CAD/CAM technique. Thanks to toughening transformation mechanism, superior mechanical properties were reported. ${ }^{11}$ Delaminations with exposure of zirconia core ${ }^{12}$ and minor ceramic chipoff reduce veneered zirconia long-term success. ${ }^{13}$ Ceramill $\mathrm{Zi}$ (AmannGirrbach, Koblach, Austria) (AG) is designed to be milled out of porously pre-sintered zirconia ceramic blanks as enlarged constructions, then sintered to full density and shrunk to the desired final dimensions.

Recently, AG also introduced new CoCr alloy that follows the same milling process (Ceramill Sintron, AG). Dry milling is possible since this soft metal block has mechanical properties similar to those of wax block. This reduces the risk of contaminating the finished materials. This method lowers milling time as well as stress on milling machines. After milling, specimens have to be sintered at $1,280^{\circ} \mathrm{C}^{14}$

The mechanical integrity and ceramic core adhesion have proven to be key factors for bilayered restorations' successful performance. Their initial bond strength and reliability after thermocycling can provide useful information of clinical behavior and predictability.

The objectives of this study were to evaluate the shear bond strength of novel pre-sintered $\mathrm{CoCr}$ alloy and to compare the results to pre-sintered zirconia core ceramics and conventional $\mathrm{NiCr}$ cast alloy with their corresponding veneering ceramics. Thermocycling effect of on shear bond strength was also investigated.

The null hypotheses were that there was no difference in shear results between tested materials. Thermocycling treatment would affect these results.

\section{MATERIALS AND METHODS}

\section{Frameworks Fabrication}

Sixty disk-shaped specimens with $15 \mathrm{~mm}$ diameter and $2 \mathrm{~mm}$ thickness were prepared $(\mathrm{n}=60)$, divided into group Si: $(n=20)$ pre-sintered CAD/CAM CoCr (Ceramill Sintron, AG); group Zi: $(n=20)$ pre-sintered CAD/CAM Zirconia (Ceramill Zi, AG); and group Wi: $(\mathrm{n}=20) \mathrm{NiCr}$ lost wax technique: (control group) (Wirobond 99, Bego, $\mathrm{GmbH}$, Bremen, Germany). Disks were manufactured from a disk-shaped three-dimensional body (STL file) construction, with $15 \mathrm{~mm}$ diameter and $2 \mathrm{~mm}$ thickness. Then, these specimens were nested into corresponding material blanks using Ceramill Match 2 Software (Table 1). First two groups were milled using Ceramill Motion 2 milling machine. Then, disks were cut out of blanks and sintered [Ceramill Sintron (Sintering furnace: Ceramill Argotherm, standard sintering program)] and [Ceramill $\mathrm{Zi}$ (sintering furnace: Ceramill Therm, standard sintering program)]. Group three wax patterns were casted in $\mathrm{NiCr}$ alloy following the manufacturer's instructions.

\section{Ceramic Layering}

Only one of the specimens surface was prepared for ceramic layering. NiCr disks were abraded with $150 \mu \mathrm{m}$ aluminum oxide airborne particle (Korox, Bego) at an angle of $45^{\circ}$ for 10 seconds from a distance of approximately $2 \mathrm{~cm}$, under 2 bar pressure. Disks were then ultrasonically cleaned in isopropyl alcohol (Vitasonic II, Vita, Bad Säckingen, Germany) for 5 minutes and allowed to dry at room temperature. The CAD/CAM specimens were also layered following the manufacturer's instructions.

Ceramic layering was processed as follows: Application of two liner firings (Vita M13 and M9, Vita zahnfabrik, Bad Saeckingen) (Vita M 13 for $\mathrm{CoCr}$ and NiCr, Vita M9

Table 1: Disk materials and their corresponding veneering ceramic

\begin{tabular}{llll}
\hline Disks & Ceramill Sintron Lot: $1404009 \mathrm{n}=20$ & Ceramill Zi Lot: 1409001 $\mathrm{n}=20$ & $\begin{array}{l}\text { Ceramill Wax: } \mathrm{n}=20 \text { [casted in NiCr } \\
\text { (Wirobond, Bego)] } \mathrm{n}=20\end{array}$ \\
Ceramic & (Vita M13 Vita zahnfabrik, Bad & (Vita M9, Vita zahnfabrik, Bad & (Vita M13, Vita zahnfabrik, Bad \\
& Saeckingen) & Saeckingen) & Saeckingen) \\
\hline
\end{tabular}


for Zirconia). The first ceramic dentin was layered using silicone molds, then fired in a furnace (Vita Furnace, Vita zahnfabrik, Bad Saeckingen), followed by the second layer and final glaze according to the manufacturer's instructions. Four millimeters ceramic thickness was standardized using a polyethylene template. The mold dimensions were increased to compensate porcelain firing shrinkage. Ceramics were condensed by slightly knocking the entire model (with the silicone mold) on a flat surface several times. After removal from the assembly, ceramic was fired. ${ }^{15}$ Ceramic thickness for all the specimens was measured with a digital caliper (Mitutoyo Manufacturing Company Ltd). ${ }^{6}$

\section{Fatigue Tests}

Specimens (20 per group) were randomly divided into two subgroups. Only one subgroup was subjected to thermocycling. Thermocycling was performed using thermocycling device (Willytec, Gräfelfing, Germany) between 5 and $55^{\circ} \mathrm{C}$ for 500 times (dwell time: 30 seconds, transfer time from one bath to the other: 5 seconds). Then, the two groups were submitted to shear bond strength test. ${ }^{16}$

\section{Shear Bond Strength Test}

Shear bond strength tests were performed using universal testing machine (Zwick ROELL Z2.5 MA 18-1-3/7, Ulm, Germany). Load was applied with a $50 \mathrm{kgF}$ load cell to substrate-adherend interface, as close as possible to substrate surface at a crosshead speed of $0.5 \mathrm{~mm} / \mathrm{min}{ }^{1}$ The stress-strain curve was analyzed with software program (TestXpert ${ }^{\circledR}$, Zwick ROELL, Ulm, Germany). Bond strength after each test $(\mathrm{MPa})$ was calculated by dividing the maximum load $(\mathrm{N})$ by ceramic surface area.

\section{Chemical Analysis of the Ceramic-Alloy Interface}

Three additional specimens from each ceramic-alloy combination were prepared to be evaluated under scanning electron microscope (SEM) and EDX spectroscopy (EDS). Prior to analysis, specimens were embedded in autopolymerizing acrylic resin (Alike, Gc America Inc.), then sectioned longitudinally using diamond saw (Kerr, Orange, CA), ground finished to 400 grit silicon carbide abrasive and polished with diamond paste in the sequence of 6,3 , and $0.25 \mu \mathrm{m}$ felt disks under water coolant irrigation (Cosmedent, Chicago, Illinois). Morphology and chemical analysis were monitored at the ceramic-alloy interface of each group using an SEM equipped with an EDS (EDAX Apollo, accelerating voltage $20 \mathrm{KV}$ ).

\section{Failure Analysis}

Specimens were analyzed using digital microscope (VHX2000D; Keyence, Osaka, Japan) at 200× magnification.
Failure modes have been classified into five types: $\mathrm{X} /$ adhesive with no opaque ceramic on metal surface, $\mathrm{Y} /$ opaque ceramic on substrate surface $<1 / 3, \mathrm{Z}$ /opaque ceramic on substrate surface $>1 / 3, \mathrm{~V} /$ opaque ceramic completely covering substrate surface, and $\mathrm{W} /$ cohesive fracture into veneering ceramic.

\section{Statistical Analysis}

Statistical Package for the Social Sciences software (IBM SPSS Statistics, v23.0; IBM Corp) was used. One-way analysis of variance was used for shear bond strength values comparison between materials and for aging treatment effect. Levene's test and Bonferroni correction were performed for multiple pairwise comparisons. Chi-square test was used for failure type analysis. Two-parameter Weibull distribution values including Weibull modulus, scale $(\mathrm{m})$ and shape $(0)$ values were calculated. p-values less than 0.05 were considered significant in all tests.

\section{RESULTS}

Failure types were mostly mixed failures. Significant difference was found among the three materials failure types, for $Y(p=0.032)$ and $Z(p=0.010)$ (Table 2 and Fig. 1).

Thermocycling had no major effect on the reported results (Table 3 ).

Considering registered Ffail, significant difference was found between the control group and milled alloys groups. No significant difference was reported between Ceramill Sintron and Ceramill Zi (Table 4).

The EDX mapping showed a net increase in oxide layer for $\mathrm{CoCr}$ and $\mathrm{NiCr}$ groups. Only very slight increase was reported for $\mathrm{Zi}$ (Table 5).

The highest Weibull parameters were obtained with the NiCr group both for the Fmax and for the adhesion parameters (Graph 1).

\section{DISCUSSION}

This study showed that porcelain bond strength was similar between the two milled CAD/CAM alloys. Significant difference was found with the control group.

Table 2: Percentage of type of failures for each material

\begin{tabular}{lllllll}
\hline $\begin{array}{l}\text { Failure } \\
\text { percentage }\end{array}$ & $X$ & $Y$ & $Z$ & $V$ & $W$ & \\
\hline ST & 2 & 17 & 1 & 0 & 0 & failure/20 \\
& $10 \%$ & $85 \%$ & $5 \%$ & $0 \%$ & $0 \%$ & \\
ZI & 1 & 15 & 2 & 0 & 2 & failure/20 \\
& $5 \%$ & $75 \%$ & $10 \%$ & $0 \%$ & $10 \%$ & \\
NiCr & 0 & 9 & 6 & 3 & 2 & failure/20 \\
& $0 \%$ & $45 \%$ & $30 \%$ & $15 \%$ & $10 \%$ & \\
p-value & 0.0611 & $0.032^{*}$ & $0.010^{*}$ & 0.056 & 0.322 & \\
\hline
\end{tabular}

*Significant difference 

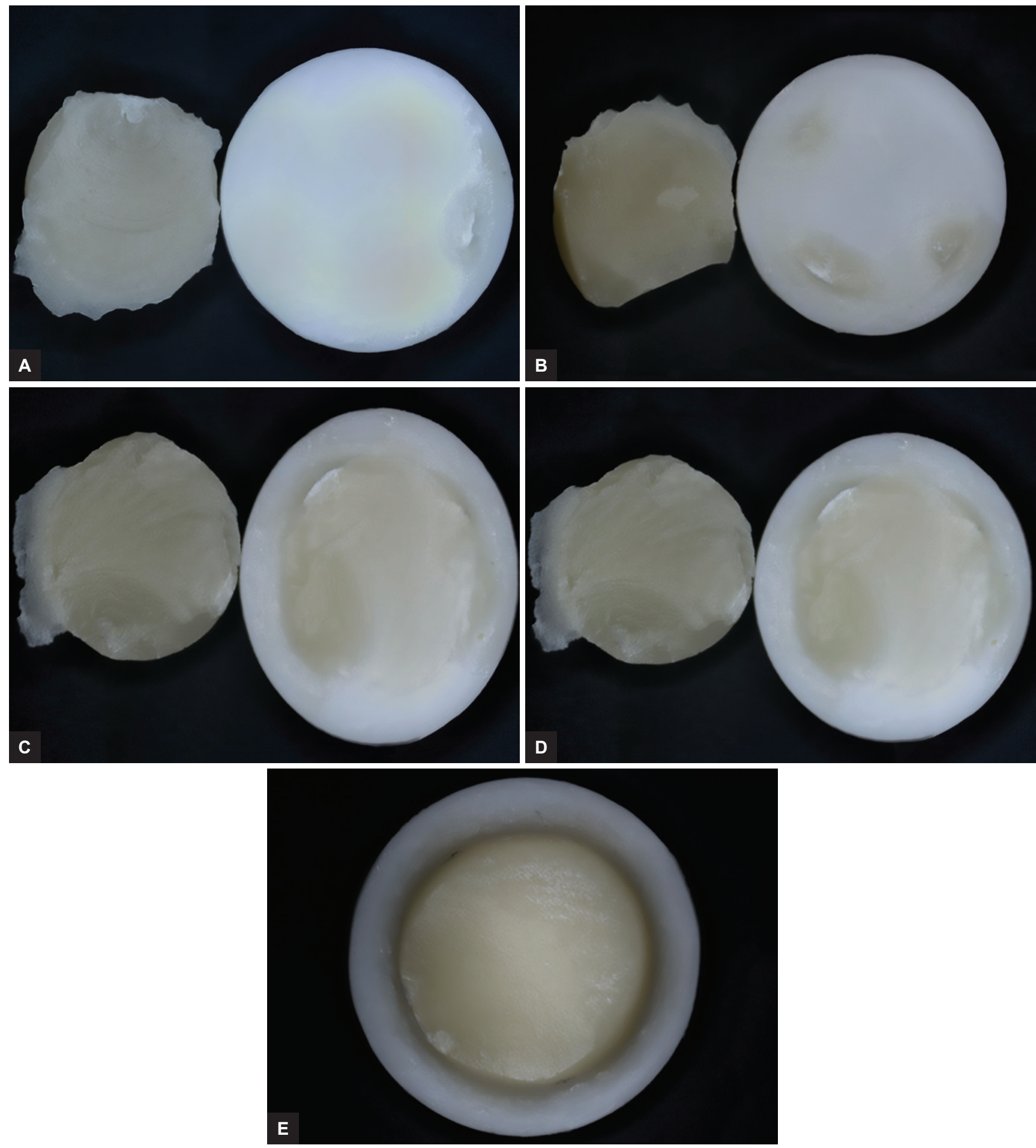

Figs 1A to E: Representative failure types on zirconia specimens. (A) Adhesive fracture with no opaque ceramic on the alloy surface: (B) opaque ceramic on the substrate surface $<1 / 3$; (C) Opaque ceramic on the subtrate surface $>1 / 3$; (D) Opaque ceramic covering the total subtrate surface; $(\mathrm{E})$ Cohesive fracture in veneering ceramic

Table 3: Impact of thermocycling for each material and failure type

\begin{tabular}{llllll}
\hline $\begin{array}{l}\text { Shear/thermo }+ \\
\text { shear/p-value }\end{array}$ & $X$ & $Y$ & $Z$ & $V$ & $W$ \\
\hline ST & 0.153 & $0.030^{*}$ & 0060 & 0.569 & 0.567 \\
ZI & 1.000 & 0.279 & 0.214 & 0.569 & 0.567 \\
NiCr & 0.569 & $0.030^{*}$ & 0.538 & $0.014^{*}$ & 0.567 \\
All groups & 0.120 & 0.348 & 1.000 & 1.000 & 1.000 \\
\hline
\end{tabular}

Table 4: Mean, standard deviation, and p-value of fail between materials

\begin{tabular}{lll}
\hline Ffail/p-value & Mean $(\mathrm{MPa})+\mathrm{SD}$ & $p$-value/all \\
\hline $\mathrm{ST}$ & $18.446 \pm(7.098)$ & 0.105 \\
$\mathrm{ZI}$ & $21.973 \pm(5.288)$ & 0.350 \\
$\mathrm{NiCr}$ & $15.706 \pm(5.879)$ & $0.000^{*}$ \\
\hline
\end{tabular}

*Significant difference; SD: Standard deviation 
Table 5: EDX oxide mapping of the three materials with and without ceramic

\begin{tabular}{lll}
\hline EDX $($ Wt \%) & Disk & Disk + ceramic \\
\hline $\mathrm{ST}$ & 6.17 & 17.12 \\
$\mathrm{Zi}$ & 11.92 & 12.88 \\
$\mathrm{NiCr}$ & 10.18 & 20.08 \\
\hline
\end{tabular}

In accordance with other publication, shear bond strength values of Si novel material were higher than those of cast control group. ${ }^{17}$ Null hypothesis was partly rejected.

Divergent results between milled alloys and cast alloy may primarily be attributed to different adhesion mechanism of cast metal and milled core materials to veneering ceramics. Different surface topographies were reported by studies between cast and milled materials. ${ }^{18}$ Whereas the most prominent role in the metal ceramic interface seems to be played by mechanical interlocking and chemical bond resulting from suitable metal oxidation and interdiffusion of ions, ${ }^{19}$ bonding mechanisms of veneering ceramics to Y-TZP surfaces remain unclear. ${ }^{20}$

Results also reported lower values than those of other researches. ${ }^{16,21}$ This is probably caused by differences in SBS methodology used in the current study and others. Bond strengths of smaller specimens are higher than those of larger specimens. ${ }^{22}$ The latter show more frequent interface flaws and higher risk of early bond failure. ${ }^{23}$ Lower values for zirconia testing, in the range of 9.4 to $12.5 \mathrm{MPa}$, were found. ${ }^{11}$ Mean of SBS to metal and Zr was recently evaluated at 24.57 and 20.88 respectively. ${ }^{24}$ Results of SBS test methods to various alloy types ranged from 8.458 to $97 \mathrm{MPa} .^{25,26}$ The SBS test method was chosen in this study due to its simplicity, ease of specimen preparation, and simple test protocol. However, some disadvantages were cited such as high standard deviations, nonuniform interfacial stresses, porosities, and specimen geometry.
Although veneering process was conducted according to manufacturer's instructions, some variations can still be related to specimen preparation. A silicone mold was prepared as a hollow cylinder. Porcelain powder was packed into the tube to reproduce the same designed ceramic. This method helped to elaborate porcelain veneer form, taking shrinkage into consideration. ${ }^{27}$ However, porcelain veneer may be damaged while removing the mold from the core. This may have decreased its bond strength. ${ }^{17}$ The SBS is affected by veneering technique, pressed ceramic showing higher scores.$^{28}$ Ceramic layering requires good dexterity, multiple applications, and adjustments to acquire definitive shape. ${ }^{29}$ Failure rate caused by fracture and exfoliation of porcelain was the highest reported..$^{30}$ However, heat-pressed ceramics have structural limit caused by defective interface. ${ }^{31}$

Weibull analysis is used to determine if the test method had a significant effect on bond test results. Test method showed influence on the study outcomes. Specimens within the same group do not fail at a single reproducible Fmax, but a distribution strength value is based on their flaw population. ${ }^{32}$ Weibull distribution is based on the theory that the strength of a loaded body is determined by the largest structural defect. ${ }^{33}$ A material with the highest Weibull modulus may be selected for a reliable clinical use. Si novel material can be considered for clinical applications.

It was suggested that groups should contain more than 10 specimens to obtain reliable conclusions. ${ }^{34}$ Each group in this study was formed of 20 samples. Fractographic analysis helps to assess the critical flaw. ${ }^{32}$ This was not the scope of the present search.

Load application technique may also have impact on the reported fail. Researcher should be aware of the wellknown problems resulting from non-uniform shear stress states at the interface, related to variations in specimens
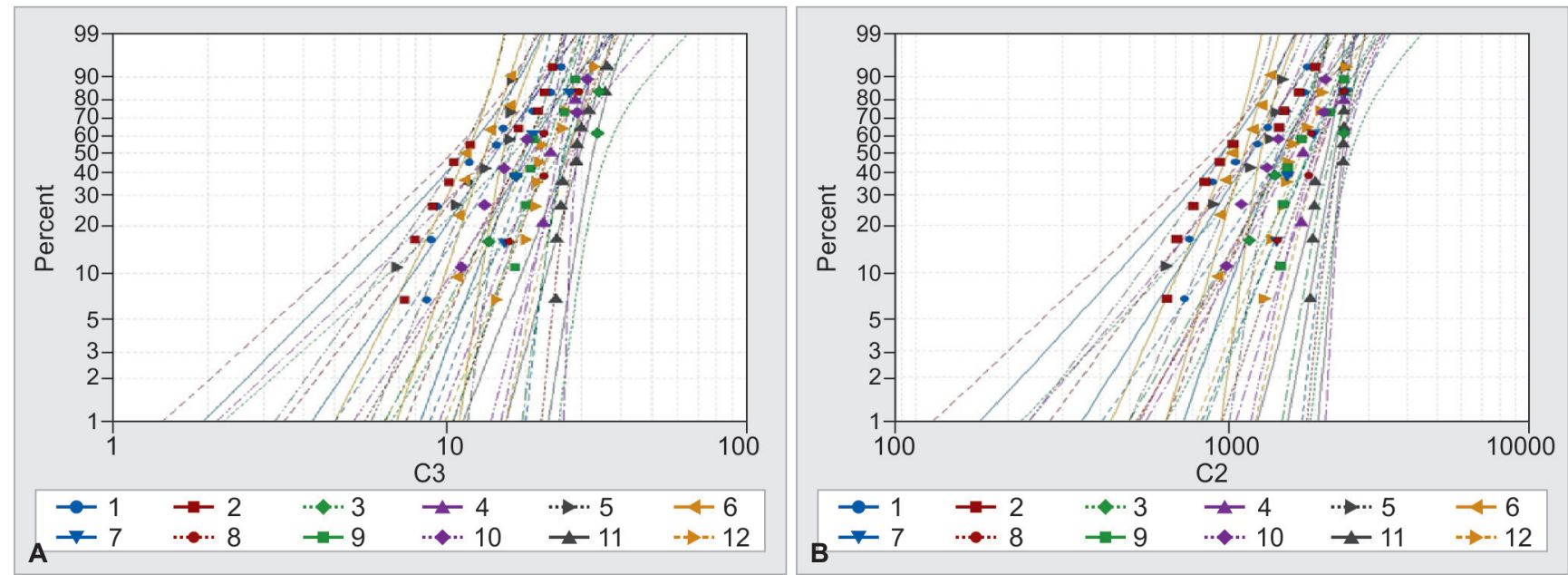

Graphs 1A and B: Probability plot with Weibull curves (95\% confidence interval) using maximum likelihood estimation, scale and shape values for (A) Fmax and (B) MPA values for all groups 
geometry and loading configuration. ${ }^{35}$ Specimens were designed to have an interface parallel to the load. ${ }^{17}$ Inappropriate test design may generate false interpretation of bond strength data. ${ }^{36}$

Some authors proposed that all materials should be subjected to fatigue conditioning before mechanical testing. ${ }^{37}$ In the current study, bond strengths values were irrespective of thermocycling exposure. Only significant difference was found for Sintron group, Y failure type $(\mathrm{p}=0.030)$; and for $\mathrm{NiCr}$ group, failure types $\mathrm{Y}$ and $\mathrm{V}$, ( $p$-values 0.30 and 0.14 respectively) (Table 3 ). Differences in all other failure types (12 subdivisions) were nonsignificant. This confirmed results reported by others. ${ }^{11}$ Second null hypothesis was therefore, partly rejected.

Moreover, microscope examination showed that most fractures were classified as mixed failures. Only two specimens from Sintron group and one from Ceramill $\mathrm{Zi}$ exhibit a full debonding of opaque from metal. This was not reported for the control group where three cases revealed a persistent opaque on substrate full surface. Previous studies reported fractures mostly adjacent to core veneer interface, ${ }^{38,39}$ while others reported mostly cohesive failure mode in metal ceramic group. ${ }^{40} 10 \%$ of the specimens showed cohesive fractures within the porcelain in groups $\mathrm{Zi}$ and Wi. Cohesive fracture happens when ceramic strength is less than that of ceramic core interfacial bond strength. This may be due to an inherent flaw into the porcelain. Fifteen specimens (75\%) in zirconia group showed mixed debonding with less than one-third ceramic remaining on the substrate. This is in contrast with other findings that presumed that fractures in zirconia restorations were mainly chipping within the porcelain. ${ }^{41}$ This is also applied to Ceramill Sintron where 17 specimens (85\%) showed mixed debonding with less than one-third ceramic remaining on the substrate. Significant difference was found when compared with the control group where only nine specimens (45\%) showed $\mathrm{Y}$ failure type. This is an important finding that will raise again the delamination occurrence and restorations ultimate failure for presintered milled alloys.

During firing cycle, thermo-mechanical stresses are created by differences in thermal contraction and expansion of alloy and porcelain. These transient and residual thermal stresses depend on thermal compatibility between porcelain and alloy. ${ }^{42}$ It is agreed that alloy should have higher CTE than porcelain (a positive expansion coefficient mismatch) to produce compressive stresses into the porcelain on cooling. ${ }^{5}$ Metal and porcelain are considered compatible if difference in CTEs is less than $1 \times 10^{-6} /{ }^{\circ} \mathrm{C}$ at a given temperature. ${ }^{43}$ Declared CTEs for Sintron and Wiron99 are $14.5 \times 10^{-6}$ $\mathrm{K}^{-1}, 13.8-14.0 \times 10^{-6} \mathrm{~K}^{-1}$ respectively, and for Vita VM
13 13.1-14 × $10^{-6} \mathrm{~K}^{-1}$. Regarding Ceramill Zi and Vita VM9, CTEs are respectively $10.4 \pm 0.5 \times 10^{-6} \mathrm{~K}^{-1}$ and $9-9.2 \times 10^{-6} \mathrm{~K}^{-1}$.

Some authors considered that oxide layer thickness formed at materials interface decreases porcelain thermal contraction coefficient and impair adhesion. ${ }^{44,45}$ The EDS analysis showed oxide layer increase for all materials after ceramic layering. However, oxide layer was thicker in the NiCr group. This may explain the lower shear bond strength values reported for the control group. We noticed also that there was no total delamination in the Wirobond 99 group (X 0\%) (Table 2). Failure may have occurred within this thick or nonhomogenous oxide layer. In contrast to other researchers' conclusions, ${ }^{45}$ negative correlation was found between oxide layer thickness and porcelain adhesion to metal. It was also reported that oxide layers of less than 1 to $2 \mathrm{~nm}$ were desirable for excellent adhesion. Thicker layers may lead to lower bond strength. ${ }^{46}$

Shear bond strength test remains relatively simple to implement in measuring porcelain-metal interface strength. ${ }^{21}$ However, several factors are implicated in porcelain fracture for metal ceramic restorations. Restoration's structure, fabrication processes, technical skills, and the bond between core and veneering porcelains are to be taken into consideration. ${ }^{3}$ If this test alone is not sufficient to predict material reliability, it may help to distinguish product $\mathrm{A}$ from product $\mathrm{B},{ }^{35}$ and to compare a novel product to a gold standard one. In this study, novel Ceramill Sintron results were higher than those of the conventional $\mathrm{NiCr}$.

\section{CONCLUSION}

From this study, it can be concluded that Novel Ceramill $\mathrm{Si}$ is a promising material for metal ceramic prostheses. While its results were comparable to that of $\mathrm{Zi}$, they were higher than conventional cast material with no effect of thermocycling. Ceramic alloy bond needs further investigations.

\section{ACKNOWLEDGMENT}

Special acknowledgment goes to Mrs Rita Hoffmann from AmannGirrbach Company for materials support.

\section{REFERENCES}

1. Lombardo GH, Nishioka RS, Souza RO, Michida SM, Kojima AN, Mesquita AM, Buso L. Influence of surface treatment on the shear bond strength of ceramics fused to cobaltchromium. J Prosthodont 2010 Feb;19(2):103-111.

2. Williams TR, Johnson CE, Winchell PG, Philips RW. Be, Li and $\mathrm{Na}$ redistribution near a porcelain $\mathrm{Ni}$ alloy interface shown by ion microprobe mass analysis. J Dent Res 1978 Feb;57(2):233-236. 
3. Benetti P, Della Bona A, Kelly JR. Evaluation of thermal compatibility between core and veneer dental ceramics using shear bond strength test and contact angle measurement. Dent Mater 2010 Aug;26(8):743-750.

4. Hattali M, Valette S, Ropital F, Stremsdoerfer G, Mesrati N, Tréheux D. Study of SiC-nickel alloy bonding for high temperature applications. J Eur Ceram Soc 2009;29:813-819.

5. Kimura H, Horng CJ, Okazaki M, Takahashi J. Thermal compatibility of titanium porcelain system. J Osaka Univ Dent Sch 1990 Dec;30:43-52.

6. Yilmaz H, Dincer C. Comparison of the bond compatibility of titanium and an $\mathrm{NiCr}$ alloy to dental porcelain. J Dent 1999 Mar;27(3):215-222.

7. Akagi K, Okamoto Y, Matsuura T, Horibe T. Properties of test metal ceramic titanium alloys. J Prosthet Dent 1992 Sep;68(3):462-467.

8. Pretti M, Hilgert E, Bottino MA, Avelar RP. Evaluation of the shear bnd strength of the union between two CoCr-alloys and a dental ceramic. J Appl Oral Sci 2004 Dec;12(4):280-284.

9. Lee KB, Park CW, Kim KH, Kwon TY Marginal and internal fit of all-ceramic crowns fabricated with two different CAD/ CAM systems. Dent Mater J 2008 May;27(3):422-426.

10. Joias RM, Tango RN, Junho de Araujo JE, Junho de Araujo MA, Ferreira Anzaloni Saavedra Gde S, Paes-Junior TJ, Kimpara ET. Shear bond strength of a ceramic to Co-Cr alloys. J Prosthet Dent 2008 Jan;99(1):54-59.

11. Guess PC, Kulis A, Witkowskia S, Wolkewitz M, Zhang Y, Strub JR. Shear bond strengths between different zirconia cores and veneering ceramics and their susceptibility to thermocycling. Dent Mater 2008 Nov;24(11):1556-1567.

12. Sailer I, Feher A, Filser F, Gauckler LJ, Luthy H, Hammerle CH. Five-year clinical results of zirconia frameworks for posterior fixed partial dentures. Int J Prosthodont 2007 Jul-Aug; 20(4):383-388.

13. Raigrodski AJ, Chiche GJ, Potiket N, Hochstedler JL, Mohamed SE, Billiot S, Mercante DE. The efficacy of posterior three-unit zirconium-oxide-based ceramic fixed partial dental prostheses: a prospective clinical pilot study. J Prosthet Dent 2006 Oct;96(4):237-244.

14. Kim KB, Kim JH, Kim WC, Kim JH. Three-dimensional evaluation of gaps associated with fixed dental prostheses fabricated with new technologies. J Prosthet Dent 2014 Dec;112(6):1432-1436.

15. Ruiz L, Readey MJ. Effect of heat-treatment on grain size, phase assemblage, and mechanical properties of $3 \mathrm{~mol} \%$ Y-TZP. J Am Ceram Soc 1996 Sep;79(9):2331-2340.

16. Vasquez VZ, Ozcan M, Kimpara ET. Evaluation of interface characterization and adhesion of glass ceramics to commercially pure titanium and gold alloy after thermal- and mechanical-loading. Dent Mater 2009 Feb;25(2):221-231.

17. Lee DH, Lee BJ, Kim SH, Lee KB. Shear bond strength of porcelain to a new millable alloy and a conventional castable alloy. J Prosthet Dent 2015 Apr;113(4):329-335.

18. Stawarczyk B, Eichberger M, Hoffmann R, NoackF, Schweiger J, Edelhoff D, Beuer F. A novel CAD/CAM base metal compared to conventional CoCrMo alloys: an in-vitro study of the longterm metal-ceramic bond strength. Oral Health Dent Manag 2014 Jun;13(2):446-452.

19. Schweitzer DM, Goldstein GR, Ricci JL, Silva NR, Hittelman EL. Comparison of bond strength of a pressed ceramic fused to metal versus feldspathic porcelain fused to metal. J Prosthodont 2005 Dec;14(4):239-247.
20. Chevalier J, Gremillard L, Virkar AV, Clarke DR. The tetragonal-monoclinic transformation in zirconia: lessons learned and future trends. J Am Ceram Soc 2009 Sep;92(9):1901-1920.

21. Choi BK, Han JS, Yang JH, Lee JB, Kim SH. Shear bond strength of veneering porcelain to zirconia and metal cores. J Adv Prosthodont 2009 Nov;1(3):129-135.

22. Weibull W. A statistical distribution function of wide applicability. J Appl Mech 1951 Sep;18:293-297.

23. Fischer J, Stawarzcyk B, Trottmann A, Haemmerle CH. Impact of thermal misfit on shear strength of veneering ceramiczirconia composites. Dent Mater 2009 Apr;25(4):419-423.

24. Abrisham S, Fallah Tafti A, Kheirkhah S, Tavakkoli MA. Shear bond strength of porcelain to a base-metal compared to zirconia core. J Dent Biomater 2017 Mar;4(1):367-372.

25. Subash M, Vijitha D, Deb S, Satish A, Mahendirakumar N. Evaluation of shear bond strength between zirconia core and ceramic veneers fabricated by pressing and layering techniques: in vitro study. J Pharm Bioallied Sci 2015 Aug;7(Suppl2): S612-S615.

26. Farzin M, Khaledi AAR, Malekpour B, Naseri MH. Evaluation of bond strength of pressed and layered veneering ceramics to nickel-chromium alloy. J Dent Shiraz Univ Med Sci 2015 Sep;16(3 Suppl):230-236.

27. Oguri T, Tamaki Y, Hotta Y, Miyazaki T. Effects of a convenient silica-coating treatment on shear bond strengths of porcelain veneers on zirconia-based ceramics. Dent Mater J 2012 Sep;31(5):788-796.

28. Ansong R, Flinn B, Chung K-H,Mancl L, Ishibe M, Raigrodski AJ. Fracture toughness of heat-pressed and layered ceramics. J Prosthet Dent 2013 Apr;109(4):234-240.

29. Ishibe M, Raigrodski AJ, Flinn BD, Chung KH, Spiekerman C, Winter RR. Shear bond strengths of pressed and layered veneering ceramics to high noble alloy and zirconia cores. J Prosthet Dent 2011 Jul;106(1):29-37.

30. De Backer H, Van Maele G, De Moor N, Van den Berghe L. Long-term results of short-span versus longspan fixed dental prostheses: an up to 20-year retrospective study. Int J Prosthodont 2008 Jan-Feb; 21(1):75-85.

31. Oh J, Song KY, Ahn SG, Park JM, Lee MH, Seo JM. Effects of core characters and veneering technique on biaxial flexural strength in porcelain fused to metal and porcelain veneered zirconia. J Adv Prosthodont 2015 Oct;7(5):349-357.

32. Burrow MF, Thomas D, Swain MV, Tyas MJ. Analysis of tensile bond strengths using Weibull statistics. Biomaterials 2004 Sep;25(20):5031-5035.

33. Quinn JB, Quinn GD. A practical and systematic review ofWeibull statistics for reporting strengths of dental materials. Dent Mater 2010 Feb;26(2):135-147.

34. McCabe JF, Carrick TE. A statistical approach to the mechanical testing of dental materials. Dent Mater 1986 Aug;2(4):139-142.

35. Scherrer SS, Cesar PF, Swain MV. Direct comparison of the bond strength results of the different test methods: a critical literature review. Dent Mater 2010 Feb;26(2):e78-e93.

36. Della Bona A, van Noort R. Shear vs tensile bond strength of resin composite bonded to ceramic. J Dent Res 1995 Sep;74(9): 1591-1596.

37. Scherrer SS, Wiskott AH, Coto-Hunziker V, Belser UC. Monotonic flexure and fatigue strength of composites for provisional and definitive restorations. J Prosthet Dent 2003 Jun;89(6):579-588.

38. Aboushelib MN, de Jager N, Kleverlaan CJ, Feilzer AJ. Microtensile bond strength of different components of core veneered all-ceramic restorations. Dent Mater 2005 Oct;21(10):984-991. 
39. Aboushelib MN, Kleverlaan CJ, Feilzer AJ. Effect of zirconia type on its bond strength with different veneer ceramics. J Prosthodont 2008 Jul;17(5):401-408.

40. Oilo G, Johansson B, Syverud M. Bond strength of porcelain to dental alloys-an evaluation of two test methods. Scand J Dent Res 1981 Jun;89(3):289-296.

41. Daou EE. Bonding mechanism of porcelain to frameworks: similarities and dissimilarities between metal and zirconia. Br J Med Med Res 2016 Jun;16(3):1-13.

42. Bagby M, Marshall SJ, Marshall GW Jr. Metal ceramic compatibility: a review of the literature. J Prosthet Dent 1990 Jan;63(1):21-25.
43. Fairhurst CW, Anusavice KJ, Hashinger DT, Ringle RD, Twiggs SW. Thermal expansion of dental alloys and porcelain. J Biomed Mater Res 1980 Jul;14(4):435-446.

44. Rosenstiel, S.; Land, M.; Fujimoto, J. Contemporary fixed prosthodontics. 5th ed. St. Louis (MO): Elsevier; 2016. p. 890.

45. Mackert JR Jr, Ringle RD, Parry EE, Evans AL, Fairhurst CW. The relationship between oxide adherence and porcelainmetal bonding. J Dent Res 1988 Feb;67(2):474-478.

46. Smith TB, Kelly JR, Tesk JA. In vitro fracture behaviour of ceramic and metal-ceramic restorations. J Prosthodont 1994 Sep;3(3):138-144. 